\title{
THE INDICATOR OF ABUNDANCE ( $N$ INDIVIDUALS/FISH) AND THE SPECIES DIVERSITY INDEX (D) FOR PARASITIC FAUNA IN SOME FISHES OF OHRID LAKE
}

\author{
${\text { Muhamir Shyqeriu }{ }^{1, *}, \text { Rigerta Sadikaj }^{1} \text {, Dritan Arapi }}^{2}$ \\ ${ }^{1 *}$ University of Tirana, Faculty of Natural Sciences, Department of Biotechnology, Tirana, Albania; \\ ${ }^{2}$ University of Tirana, Faculty of Natural Sciences, Flora and Fauna Research Center, \\ Tirana, Albania;
}

*Corresponding Author Muhamir Shyqeriu, e-mail: rsadikaj@hotmail.com; d_arapi@hotmail.com;

Received March 2021; Accepted April 2021; Published May 2021;

DOI: $\underline{\text { https://doi.org/10.31407/ijees11.316 }}$

\begin{abstract}
In the period from 2015 to 2017 in three areas of Ohrid Lake (west and south shore or the Albanian part of the lake) parasites were analyzed for several species of fish that populate this basin. The sampled fish were bleak (A.scoranza), chub (S.cephalus), common roach (R.rutilus), Ohrid gudgeon (G.ohridanus), Albanian roach (P.pictum), Western Balcan barbell (B.rebeli), European eel (A.anguilla), crucian carp (C.carassius), belvica (A.ohridana), common carp (C.carpio) and Ohrid brown trout (S.letnica). Two population parameters were evaluated for parasites; the indicator of abundance ( $n$ individuals/fish) and the species diversity index (D). The highest average value for abundance was calculated for Gyrodactylis sp (Monogenea) (10.8 \pm 7.339 individuals/fish). We found this helminth as an ectoparasite in Ohrid brown trout. We calculated the smallest abundance for Pomphorhynchus laevis (Acanthocephala) $(0.41 \pm 0.247$ individuals / fish). We found this endoparasite in Western Balcan barbell and Ohrid brown trout. According to the seasons, the average values for the species diversity index (D) of the parasitofauna (parasitic fauna) were: Spring: $\mathrm{D}=0.95 \pm 0.021$; Summer: $\mathrm{D}=0.89 \pm 0.029$ and Autumn: $\mathrm{D}=$ $0.86 \pm 0.007$. The $\mathrm{D}$ values we calculated for the three seasons were generally high, representing parasitic communities with high diversity.
\end{abstract}

Keywords: Ohrid Lake, parasitic fauna, Ohrid trout, Western balcan barbell, Albanian roach, Ohrid gudgeon, abundance, diversity index, heteroxenous parasites, monoxenous parasites. 